AAFP

Ann Fam Med 2013;13:287-288. doi: 10.1370/afm.1792.

\section{AAFP CELEBRATES NEW RECRUITS TO FAMILY MEDICINE, ACKNOWLEDGES WORK AHEAD}

Pause for just a moment to cheer this fact: on March 20,2015, 3,060 graduating medical students choose a career in family medicine.

That's the news just released by the National Resident Matching Program (NRMP) for the annual celebratory event commonly referred to as the Match.

And with that announcement comes the realization that for the 6th straight year, the family medicine match rate ticked upward. Furthermore, 3,216 family medicine residency positions were offered in 2015, an increase of 84 positions compared to 2014 .

That overall family medicine fill rate of $95.1 \%$ down slightly from $95.8 \%$ in 2014 -represents 60 more positions accepted by graduates compared to last year.

(Read an in-depth analysis http://www.aafp.org/ medical-school-residency/program-directors/nrmp.html of the 2015 Match provided by the AAFP's Medicine Education Division.)

The AAFP's count of students matching to family medicine includes students who matched into traditional family medicine residency programs as well as into programs that combine family medicine education with other focused training. Those additional programs are family medicine/emergency medicine, family medicine/preventive medicine, family medicine/medicine and family medicine/psychiatry.

"The Academy congratulates and welcomes these new family medicine recruits," said AAFP President Robert Wergin, MD, of Milford, Nebraska, in an interview with AAFP News. "When these residents complete their training programs, there will be plenty of patients across the country eager to welcome new family physicians to their communities."

All the well-wishing must be tempered by this sobering reality: The number of US seniors choosing family medicine slowed at an unexpected rate in 2015, to 1,422 -with just 6 more US seniors lining up for the specialty than last year.

Although the Academy will work in to determine specific factors for that slowing, Wergin pointed to a health care environment in which policy makers and payers have caused instability by shifting positions, reversing decisions and changing the rules_-sometimes simultaneously.
"This uneven environment likely is taking its toll on medical students who are anxious to finish their clinical training and move on with their careers," said Wergin.

In a press release http://www.aafp.org/media-center/ releases-statements/all/2015/match-2015.html the AAFP issued, Wergin put it this way, "We saw a consistent and increasing growth in US medical students matching to family medicine during the implementation of health system reforms that emphasized the importance of comprehensive primary medical care. That has slowed down as policy makers have pulled back from supporting primary medical care."

Wergin highlighted the country's need for more primary care physicians as the health care system continues to change.

"The increase we're seeing needs to accelerate dramatically if Americans are going to have necessary access to primary medical care," Wergin said. "The American health care system is evolving from one that reacts to disease with expensive tests and rescue treatments to one that prevents disease and helps avoid complications from chronic conditions. That kind of system will need the expertise of many more primary care physicians working with a team of health professionals."

\section{Additional Primary Care Highlights}

As the AAFP pointed out in its initial analysis of the 2015 NRMP match results, family medicine trumped all the other primary care specialists in terms of residency positions offered and filled. In fact, according to that analysis, family medicine routinely fills about $80 \%$ of all primary care positions.

Other Match data singled out by the AAFP analysis show that:

- Primary care internal medicine filled 339 positions in 2015, 6 more than in 2014

- Medicine pediatrics filled 379 positions in 2015, 17 more than last year

- Primary care pediatrics filled 74 spots, 1 fewer than in 2014 and

- Medicine/preventive medicine offered and filled 7 positions in 2015, the same number as recorded in 2014.

Overall, the AAFP noted that the average fill rate for all primary care specialties in 2015 was $96 \%$; $49.2 \%$ of positions were filled by US seniors - the same percentage recorded in 2014.

\section{Student Interest Grows}

Stan Kozakowski, MD, director of the AAFP Medical Education Division, echoed Wergin's concern about slow growth reflected by some of the numbers.

"This year's flattening of interest by an important segment of applicants is obviously disappointing." said 
Kozakowski. "Clearly more work needs to be done on many fronts to inspire US allopathic seniors to select a career in family medicine." he added.

But he pointed out statistics that support the idea that medical students do have a strong interest in learning more about family medicine.

For instance, AAFP records show consistent strong increases in the number of medical students attending the AAFP's annual event for its younger members - the National Conference of Family Medicine Residents and Medical Students http://www.aafp.org/events/nationalconference.html—set in 2015 for July 30 to August 1.

The annual conference attendance numbers -805 in 2011, 889 in 2012, 1,028 in 2,013 and 1,209 in 2014-show pumped-up interest in the specialty.

And then there are reports from family medicine interest groups http://www.aafp.org/medical-schoolresidency/fmig/connect.html (FMIGs)—a giant network of support established by the AAFP in 1995 as a way to, among other things, encourage promotion of family medicine on medical school campuses across the country.

Data from the AAFP's annual FMIG Activity Survey for the 2014-2015 academic year showed that not a single FMIG reported decreasing interest in family medicine at its school.

Furthermore, the report highlighted a $10 \%$ jump in the number of FMIGS that showed increasing interest in family medicine (from $43 \%$ to $53 \%$ ). And this academic year matched the 2013-2014 record for the largest national FMIG network since the its inception.

The survey was completed by 145 FMIGs, including 7 groups on US medical school campuses without departments of family medicine (of which there are 10).

\section{Call to Action}

As for swelling the ranks of family physicians to meet population demands, Wergin issued a call to action to his colleagues.

"Students begin medical school with a strong altruistic sense of wanting to take care of patients. Along the way, outside influences take their toll and students lose sight of what drove them to medicine in the first place. We as family physicians must do our part by serving as positive role models and mentors to these students." said Wergin.

"We as an academy must continue our work with policymakers to ensure that the number of family medicine training positions continues to grow and that payment for primary care services is commensurate with the skill level we bring to our patients.

The future of health care delivery in our country is at stake," he added.

Sherri Porter

AAFP News Department

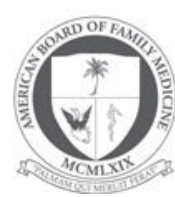

From the American

Board of Family Medicine

\section{ABFM TO SIMPLIFY MOC FOR FAMILY PHYSICIANS AND MAKE IT MORE MEANINGFUL: A FAMILY MEDICINE REGISTRY}

The American Board of Family Medicine (ABFM) launches the start of a Family Medicine Registry with a study called the Trial of Aggregate Data Exchange for Maintenance of certification and Raising Quality (TRADEMaRQ) study. This study is supported by the US Agency for Healthcare Research and Quality and is the first phase of a nearly $\$ 7$ million investment by the ABFM to make MOC easier and more meaningful, to help physicians turn their EHR data into useful information, and to support PQRS, Meaningful Use, and other reporting needs. The ABFM is the first board to sponsor a registry and the first clinical registry to support MOC.

\section{TRADEMaRQ: Registry Phase I}

TRADEMaRQ is the first stage of the registry and will test a way to automatically collect data for the quality improvement portion of MOC — not just for a handful of patients, but for all patients in your panel. This relieves doctors of the time-consuming task of collecting and submitting the information by hand. TRADEMaRQ will also give physicians feedback about their performance as they as they do MOC activities to help them see where they can make the greatest improvements, for example by increasing rates of recommended vaccinations or cancer screenings, or ensuring consistent medication use by patients with chronic conditions. The TRADEMaRQ research team will study whether performance feedback affects the Self-Assessment Modules and Practice Performance Modules physicians choose, and if it improves quality. TRADEMaRQ is a win-win-win proposition for family physicians who already receive quality measures from their system or EHR by streamlining submission for MOC_-no more hand-entering data. The ABFM and researchers will learn what might help providers quickly and effectively improve their practice; and patients will benefit from physicians who have both up-to-date medical knowledge and more time for taking care of patients.

TRADEMaRQ has 3 aims:

- To assess whether quality measures of family physi- 